\title{
CypB promotes cell proliferation and metastasis in endometrial carcinoma
}

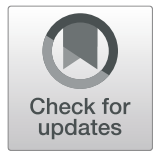

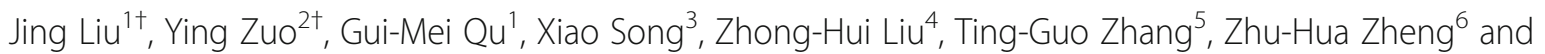
Hong-Kun Wang ${ }^{7 *}$

\begin{abstract}
Background: The molecular pathogenesis of endometrial cancer is not completely understood. CypB upregulated in many cancers, however, its role in endometrial carcinoma has not been studied. Here, we determine the effect of CypB on the growth of endometrial cancer.

Methods: In this study, we examined the expression of CypB in endometrial cancer tissues using immunohistochemistry. CypB silenced in HEC-1-B cell line by shRNA. CCK-8, colony formation assays, wound healing assays, and transwell analysis were performed to assess its effect on tumor cell proliferation and metastasis. Furthermore, microarray analysis was carried out to compare the global mRNA expression profile between the HEC-1-B and CypB-silenced HEC-1-B cells. Gene ontology and KEGG pathway enrichment analysis were performed to determine the potential function of differentially expressed genes related to CypB.
\end{abstract}

Results: We found that CypB was upregulated in endometrial cancer, inhibit CypB expression could significantly suppress cell proliferation, metastasis, and migration. We identified 1536 differentially expressed genes related to CypB (onefold change, $p<0.05$ ), among which 652 genes were upregulated and 884 genes were downregulated. The genes with significant difference in top were mainly enriched in the cell cycle, glycosphingolipid biosynthesis, adherens junctions, and metabolism pathways.

Conclusion: The results of our study suggest that CypB may serve as a novel regulator of endometrial cell proliferation and metastasis, thus representing a novel target for gene-targeted endometrial therapy.

Trial registration: YLYLLS [2018] 008. Registered 27 November 2017.

Keywords: Endometrial cancer, Cyclophilin B, Proliferation, Microarray

\section{Background}

Endometrial cancer represents a group of epithelial malignant tumors occurring in the endometrium and is one of the three most common malignant tumors of the female genital tract. Seventy-five percent of the patients are diagnosed in the early phase, and the 5 -year survival rate was $65-92 \%[1,2]$. The molecular pathogenesis of

\footnotetext{
*Correspondence: annie_coco@163.com

${ }^{+}$Jing Liu and Ying Zuo contributed equally to this work.

'Department of Gynaecology and Obstetrics, Shanghai General Hospital, Shanghai Jiao Tong University School of Medicine, Shanghai, China Full list of author information is available at the end of the article
}

endometrial cancer involves abnormalities in many genes and signaling pathways. For example, mutations in P53, increased microsatellite instability, mutations in PTEN, and abnormalities in the Notch signaling pathway all lead to uncontrolled cell proliferation and apoptosis, which in turn lead to the occurrence and development of endometrial cancer [3-6]. At present, the molecular pathogenesis of endometrial cancer is not entirely understood, and further research is warranted to develop successful therapies.

Cyclophilins are highly conserved proteins that are ubiquitously expressed intracellularly. They were first

C C The Author(s). 2021 Open Access This article is licensed under a Creative Commons Attribution 4.0 International License, which permits use, sharing, adaptation, distribution and reproduction in any medium or format, as long as you give appropriate credit to the original author(s) and the source, provide a link to the Creative Commons licence, and indicate if changes were made. The images or other third party material in this article are included in the article's Creative Commons licence, unless indicated otherwise in a credit line to the material. If material is not included in the article's Creative Commons licence and your intended use is not permitted by statutory regulation or exceeds the permitted use, you will need to obtain permission directly from the copyright holder. To view a copy of this licence, visit http://creativecommons.org/licenses/by/4.0/. The Creative Commons Public Domain Dedication waiver (http://creativecommons.org/publicdomain/zero/1.0/) applies to the data made available in this article, unless otherwise stated in a credit line to the data. 
recognized as host cell receptors for the potent immunosuppressive drug cyclosporin A [7, 8]. They act as molecular chaperones that fold, translocate, and process newly synthesized proteins. There are 16 types of human cyclophilins, cyclophilins A (СурA) and СypB being the two most abundant and the most studied ones. Li et.al using proteomics first report cyclophilin A upregulated in endometrial carcinoma serve as a potential prognostic factor [9], and up-regulation of cyclophilin A could render resistance to chemotherapeutic-induced apoptosis in cancer cells [10]. CypA also been found to be up-regulated in paclitaxel-resistant endometrial cells, and knockdown of CypA could reverse the paclitaxel-resistant through suppression of MAPK kinase pathways [11].

Cyclophilin B (СурB) is a $21 \mathrm{kDa}$ peptidyl-prolyl cistrans isomerase [12] that is expressed in the endoplasmic reticulum (ER) lumen [13] and nucleus [14]. It has been implicated in hepatitis virus replication [15], immunosuppression [16], chemotaxis [17], and prolactin signaling [18]. Moreover, its increased expression may significantly contribute to the pathogenesis of human breast cancer [19], myeloma [20], hepatic carcinoma [21], gastric cancer [22], head and neck squamous cell carcinoma [23], and glioblastoma [24]. Finally, it has also been used as a serum biomarker for the early detection of pancreatic cancer [25]. However, to date, few study has investigated the role of СypB in endometrial cancer.

Hence, to determine the effect of CypB on the growth of endometrial cancer, we aimed to assess its expression in endometrial tissues and CypB-silenced HEC-1-B cells and measure the relative gene expression with microarray analysis.

\section{Methods}

\section{Cell lines and transient transfection}

The HEC-1-B cells were purchased from the Chinese Academy of Sciences (Shanghai, China). The cells were cultured in modified Eagle's medium (Gibco, Life Technologies, Carlsbad, CA, USA) supplemented with 10\% fetal bovine serum (FBS, Gibco, Grand Island, NY, USA). And cell lines were maintained at $37^{\circ} \mathrm{C}$ in a humidified atmosphere of $5 \% \mathrm{CO}_{2}$.

The lentivirus-expressed CypB-specific short hairpin RNA (shRNA) was used to knock down the expression of CypB and negative control shRNA (NC-shRNA) as control. These shRNAs were used for transfection in the HEC-1-B cell line following the manufacturer's protocol.

\section{Sample collection}

All the tissue samples were collected via biopsy of surgical resection without chemotherapy or radiotherapy between December 2017 and September 2018 in the department of Gynecology, Affiliated Yantai Yuhuangding Hospital (Yantai, Shandong, China). The study was approved by the Ethics Committee of Yantai Yuhuangding Hospital on November 27, 2017 (registration number: YLYLLS [2018] 008). All samples were collected after obtaining written informed consent. The samples were snap-frozen in liquid nitrogen and stored at $-80^{\circ} \mathrm{C}$ before RNA extraction or generation of formalin-fixed, paraffinembedded tissue sections for immunohistochemistry.

\section{Cell proliferation and clone formation}

Cell proliferation was determined using the Cell Counting Kit-8 assay (CCK-8; Beyotime Biotechnology, Shanghai, China) per the manufacturer's instructions. Cells in the logarithmic growth phase $\left(1 \times 10^{4}\right.$ cells $/ \mathrm{mL}$ per well $)$ were grown in 96-well plates in medium containing $10 \%$ FBS in an incubator with $5 \% \mathrm{CO}_{2}$ at $37{ }^{\circ} \mathrm{C}$ for $72 \mathrm{~h}$ after transfection. Afterward, $10 \mathrm{~mL}$ of CCK- 8 solution was added to each well, and the plates were incubated for an additional $4 \mathrm{~h}$. The absorbance in each well was measured at a wavelength of $450 \mathrm{~nm}$ with a microplate reader.

For clone formation, HEC-1-B cells were transfected with CypB-shRNA for $48 \mathrm{~h}$ and were collected and seeded in triplicate into 6-well plates at a density of 1000 cells $/ \mathrm{mL}$ per well. The cells were incubated for 10 days at $37{ }^{\circ} \mathrm{C}$ in a $5 \% \mathrm{CO}_{2}$ atmosphere. They were then fixed with $4 \%$ paraformaldehyde for $30 \mathrm{~min}$ and stained with Giemsa (Beyotime Biotechnology) for $20 \mathrm{~min}$. After washing with double-distilled $\mathrm{H}_{2} \mathrm{O}$ several times, images of the cell plates were taken (Canon, Inc., Tokyo, Japan).

\section{In vitro wound healing}

The wound-healing assay was performed to evaluate cell migration. Cells were seeded onto $35 \mathrm{~mm}$ dishes. After cells reached over $90 \%$ confluence, using a sterile pipette tip to make a scratch through the confluent monolayer. The medium was changed and cells were cultured for $24 \mathrm{~h}$. The percent wound closure was calculated for four randomly chosen fields.

\section{Invasion assays}

For the invasion assay, 105 cells in serum-free medium were placed into the upper chamber of the insert with Matrigel (BD Biosciences, Franklin Lakes). After $24 \mathrm{~h}$ of incubation at $37^{\circ} \mathrm{C}$, we removed the cells remaining in the upper chamber or on the upper membrane. The number of cells adhering to the lower membrane of the chambers was counted after staining with a solution containing $0.1 \%$ crystal violet (Beyotime Institute of Biotechnology, Beijing, China) and 20\% methanol.

\section{RNA extraction, reverse transcription, qRT-PCR, western blot, and microarray analysis}

Total RNA was extracted using TRIzol, and cDNA was synthesized with the PrimeScript RT reagent Kit (TaKaRa, Dalian, China). Gene expression was assessed 
by qRT-PCR using SYBR Premix Dimer Eraser (Perfect Real Time, TaKaRa) assay kits. Relative fold changes in expression were calculated using the comparative $\mathrm{Ct}$ $\left(2^{-\Delta \Delta C t}\right)$ method.

Total protein was collected from cells treated with RIPA lysis buffer, separated by sodium dodecyl sulfatepolyacrylamide gel electrophoresis (SDS-PAGE) and then transferred onto PVDF membrane (Millipore, Bedford, MA). Primary antibodies used in this study were shown as follows: rabbit polyclonal antibodies for CypB, Ang2 (immunoway, USA), and VEGF (Weiao, China). Betaactin protein (Santa Cruz, CA) was used as a loading control.

The RNA samples collected $72 \mathrm{~h}$ after lentivirus transfection were submitted to Phalanx Biotech (Hsinchu, Taiwan) for microarray analysis. We used the Phalanx Human OneArray Plus Gene Expression Profiling platform 6.1 to analyze the CypB-mediated alterations of mRNA expression.

\section{Immunohistochemistry (IHC)}

Sections $(4 \mu \mathrm{m})$ were cut from the constructed TMA blocks, deparaffinized, and rehydrated. Heat-induced epitope retrieval was performed onboard of the Leica Bond RX platform at $100^{\circ} \mathrm{C}$ using EDTA buffer ( $\mathrm{pH}$ 9.0, Leica) for $20 \mathrm{~min}$, followed by $15 \mathrm{~min}$ of incubation with anti-CYPB antibody (\#43603, Cell Signaling Technology, Danvers, MA, USA) or anti- $\beta$-catenin antibody (\#8480, Cell Signaling Technology) at room temperature and with Bond ${ }^{\mathrm{mm}}$ Polymer Refine Detection kit (Leica Biosystems, Buffalo Grove, IL, USA) for $8 \mathrm{~min}$. The reaction was visualized using 3,3'-diaminobenzidine tetrahydrochloride for $10 \mathrm{~min}$ and with hematoxylin as a counterstain. Scoring was performed by pathologists (MK, PR) using a Nikon Eclipse microscope on TMA glass slides at 20x magnification. Tissues were scored for CypB expression, and the scoring system reflected the extent and intensity of staining: the intensity was assigned a score of $0,1,2$, or 3 , representing negative, weak, moderate, or strong expression, respectively; while the extent was assigned a score of $0,1,2,3$ or 4 , representing $<5,6-25$, $26-50,51-75$ and $>75 \%$ of cells stained. The overall quantitation of the score was obtained by multiplying the average intensity and score of five different highpower fields (at $400 \times$ magnification). The samples were divided into two groups based on final staining scores, which ranged from 0 to 7 : the high expression group (scores of $\geq 4$ ) and the low expression group (scores of $<4)[26]$.

\section{Gene ontology functional and pathway enrichment analysis}

GO (gene ontology) and KEGG pathway enrichment analysis was used for differentially expressed genes
(DEGs) using the DAVID database. FDR values of $<0.05$ were set as the cut-off criterion for the two analyses.

\section{Statistical analysis}

Statistical analysis was performed using SPSS software, version 18.0 (SPSS, Chicago, IL, USA). The chi-square test was used to determine the differences in age and tumor grades between high and low expressed CypB groups. Differences between two groups were analyzed using Student's $t$-test for comparison of two groups or by one-way analysis of variance for comparison of more than two groups. $P$ values of $<0.05$ were considered statistically significant.

\section{Results \\ CYPB was overexpressed in endometrial cancer}

Twenty-four normal endometrium tissue (control), 50 of atypical complex hyperplasia, and 96 endometrial cancer tissues were used to validate protein expression by immunohistochemistry. CypB expression was significantly higher in atypical complex hyperplasia and endometrial cancer tissues compared with normal endometrium tissues (Fig. 1), suggesting that higher expression of CypB is associated with the progression of endometrial cancer. Furthermore, no significant association was observed between CypB expression and patient age or tumor stages (Table 1).

\section{Downregulation of CypB inhibits HEC-1-B cell proliferation and metastasis}

To investigate the role of CypB in endometrial cancer, we treated the HEC-1-B cell line with CypB-shRNA. CypB-shRNA significantly reduced CypB expression both in mRNA and protein levels (Fig. 2a), indicating that a highly efficient knockdown of CypB expression was achieved.

Microscopic observation of the HEC-1-B cells was transfected with CypB-shRNA or NC-shRNA showed a decrease in cell proliferation after the downregulation of CypB. The results of the CCK- 8 assay indicated that, compared to control cells, the proliferation rate of CypB-knockdown HEC-1-B cells decreased $72 \mathrm{~h}$ after transfection (Fig. 2b). CYPB silencing in HEC-1-B cells substantially reduced colony formation (Fig. 2c). The wound-healing assay showed that the downregulation of CypB in HEC-1-B cells was associated with significantly slow cell migration (Fig. 2d). Transwell assays with matrigel demonstrated that HEC-1-B CypB ${ }^{\text {-shRNA }}$ cells had a lower invasive activity than HEC-1-B NC-shRNA vector cells ( $72 \pm 1$ vs. $145 \pm 1, p<0.01$; Fig. 2 e). All these results demonstrated that downregulated $\mathrm{CypB}$ inhibits HEC-1-B cell proliferation and metastasis in vitro. 


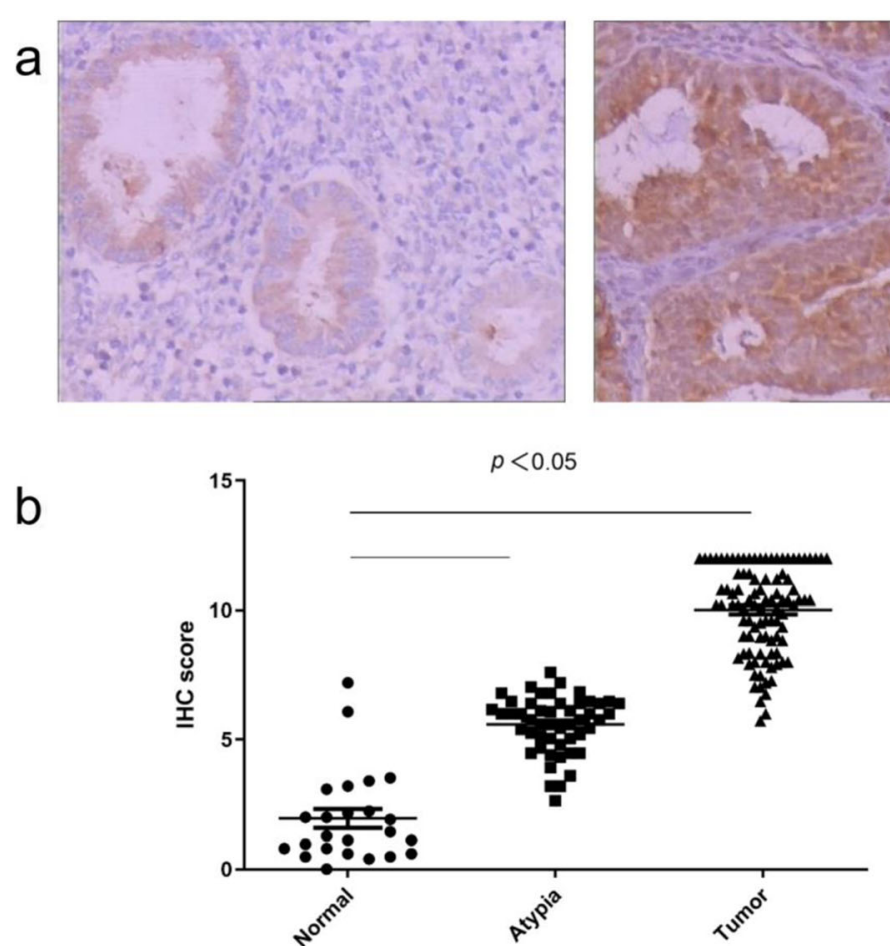

Fig. 1 CypB is overexpressed in endometrial cancer. a Representative photomicrographs of immunohistochemical staining for CypB among endometrial tissue samples are presented. b Statistical analysis of relative CypB expression levels in normal tissues, atypic tissues, and endometrial tissues. These findings indicate that CypB was significantly upregulated in tumor tissues

Identification of DEGs in endometrial cancer cell with downregulated CypB expression

We performed a microarray analysis, comparing the global mRNA expression profile between HEC-1-B and CypB-knockdown HEC-1-B cells. A volcano plot of the identified quality-controlled genes $(p<0.05$; fold change, $>1$ ) is presented in Fig. 3a. The microarray identified 1536 differentially expressed mRNAs in total, of which 652 were upregulated and 884 downregulated in the

Table 1 The CypB expression between age and tumor stages

\begin{tabular}{llllll}
\hline \multicolumn{5}{c}{} & \multicolumn{3}{c}{ CypB expression levels } & & \\
& & High & Low & Ratio (high/low) & $P^{*}$ \\
\hline Characteristic & $\mathrm{N}(\%)$ & & & \\
Ages & & & & & 0.916 \\
$<55$ & 39 & 16 & 23 & & \\
$\geq 56$ & 57 & 24 & 33 & & \\
Stage & & & & 1.43 & \\
Tis + I & 68 & 40 & 28 & 1.55 & \\
II + III & 28 & 17 & 11 & 1.43 & \\
Low (I + II) & 85 & 50 & 35 & 7 & \\
High (III) & 8 & 7 & 1 & & \\
\hline
\end{tabular}

* Chi-square test was used
CypB-knockdown group. A heat map was generated to show genes that were previously identified as significantly upregulated in HEC-1-B cells (Fig. 3b).

\section{GO functional and pathway enrichment analysis}

GO and pathway enrichment analysis showed that the DEGs were significantly enriched in the cell cycle, glycosphingolipid biosynthesis, adherens junctions, and metabolism pathways. Important genes and pathways involved in this process are shown in Fig. 3c.

\section{Validation of differentially expressed RNA by qRT-PCR}

To evaluate the reliability of microarray data, we verified the expression of five differentially expressed mRNA in HEC-1-B cells by qRT-PCR assay. As shown in Fig. 3d, the mRNA expression of SREBF1, SPP1, PPIB, and PLAT was significant downregulation in the CypBknockdown cells. While the CDKN1A mRNA shown a much higher expression in the CypB-knockdown cells. All these results were consistent with the microarray data.

\section{Discussion}

Endometrial carcinoma remains one of the leading causes of death among women, it is crucial to novel molecular targets for its diagnosis, prognosis, and treatment 


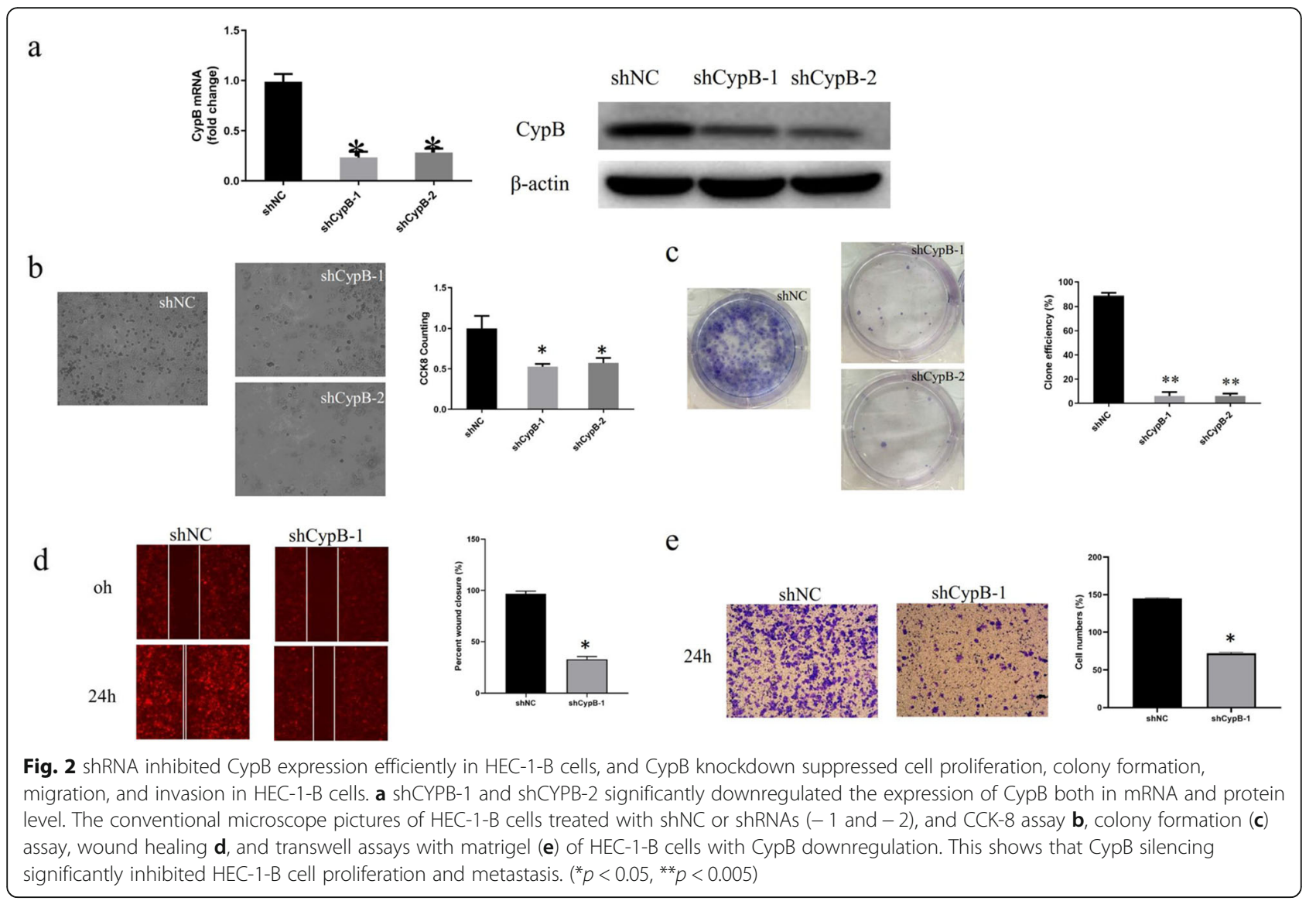

for improving the clinical strategy and outcome for this disease. Cyclophilins have been implicated in a variety of cancers; however, their expression has not been studied in endometrial carcinoma. In the present study, we screened the CypB expression pattern in endometrial cancer and found that CypB was an oncogene, which was upregulated in endometrial cancer, and downregulation of CypB inhibits HEC-1-B cell proliferation and metastasis.

Recent studies have found that CYPA expression is implicated in several cancers, including lung cancer [27, 28], pancreatic cancer [29,30], hepatocellular cancer [31], and buccal squamous cell carcinoma [32], and that it might play a role in apoptosis through the activation of caspases and apoptosis-inducing factor. A study with twodimensional gel electrophoresis and MALDI-Q-TOF MS/ MS-based proteomics approach found that overexpression of CYPA is significantly correlated with a low degree of cancer differentiation, and its overexpression was associated with decreased survival in endometrial carcinoma [9].

On the other hand, the structurally similar CypB, which was found in the endoplasmic reticulum, has been implicated in STAT3 activation and the generation of reactive oxygen species in cancer cells [24]. CypB facilitates the transcriptional activity of STAT5 by inducing the release of the repressor PIAS3, resulting in significantly enhanced STAT5-mediated gene expression [14, 18]. At the cell surface, СypB also serves as a ligand for the CD147 receptor [33], which regulates MAPK activation, motility, calcium transport [33-35], and the expression of the pro-apoptotic protein BIM [36]. Gene expression studies revealed that СypB is highly upregulated in malignancies. Ablation of CypB expression in glioblastoma multiforme cells suppresses several canonical oncogenic signaling pathways, including mutant P53, MYC, and CHK1. Teng and colleagues revealed that СурB was overexpressed in NSCLC and inhibition of $\mathrm{CypB}$ could suppress cell proliferation, migration, invasion, and angiogenesis via regulating the STAT3 pathway [37]. Notably, angiogenesis plays an important role in tumor progression. In this study, we detected the expression of VEGF and Ang2, which are two important angiogenesis-related proteins, and we found that VEGF expression was starkly been inhibited with the downregulation of $\mathrm{CypB}$, while not for Ang2 (Figure S1). CM Holland and colleagues found that VEGF-B mRNA was significantly lower in endometrial cancer than benign endometrium, while the expression level of Ang2 mRNA in endometrial carcinoma was higher than that in benign endometrium, but there was no statistical significance. 


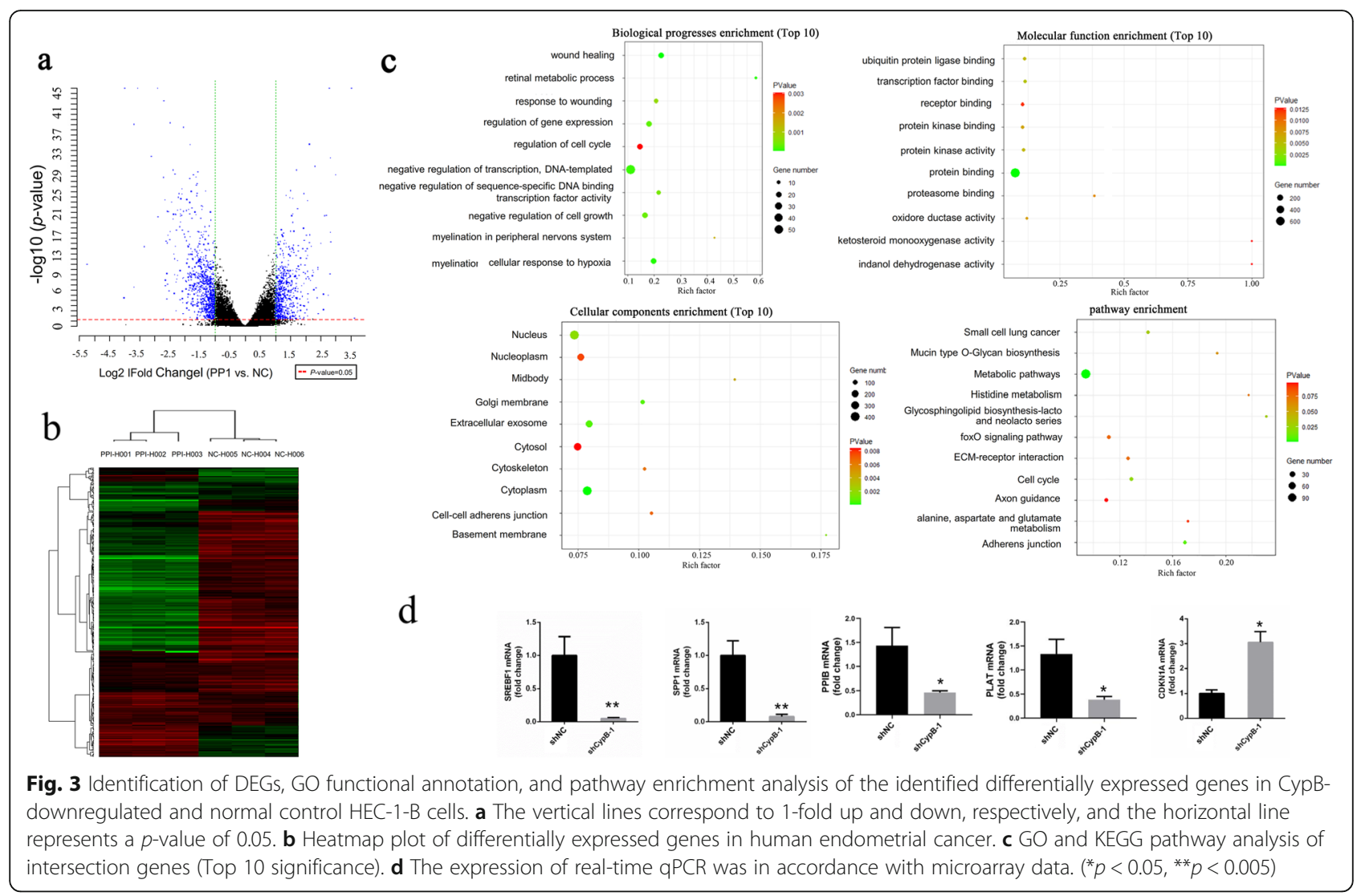

The results of this study are consistent with ours at the mRNA level [38].

\section{Conclusions}

In this study, we demonstrated endometrial tumor tissue exhibited a significantly higher expression of CypB, suggesting that CypB expression could be considered an effective indicator for the clinical outcome of endometrial cancer. Furthermore, our results demonstrate that CypB acts as an oncogene in endometrial cancer.

\footnotetext{
Abbreviations

CypA: Cyclophilins A; CypB: Cyclophilins B; shRNA: Short hairpin RNA; NC: Negative control; CCK8: Cell Counting Kit-8; qRT-PCR: Quantitative real-time PCR; SDS-PAGE: Sodium dodecyl sulfate-polyacrylamide gel electrophoresis; PVDF: Polyvinylidene fluoride; IHC: Immunohistochemistry; TMA: Terminal Market Association; EDTA: Ethylenediamine tetraacetic acid; GO: Gene ontology; KEGG: Kyoto Encyclopedia of Genes and Genomes; FDR: False discovery rate; STAT5: Signal transducer and activator of transcription 5; PIAS3: Protein inhibitor of activated STAT3; CHK1: Cell cycle checkpoint kinase 1; VEGF: Vascular endothelial growth factor; Ang2: Angiopoietin 2
}

\section{Supplementary Information}

The online version contains supplementary material available at https://doi. org/10.1186/s12885-021-08374-7.

Additional file 1.

Additional file 2.
Acknowledgments

We are grateful to the patients who participated in this study.

\section{Authors' contributions}

$J \mathrm{~L}, \mathrm{YZ}$, and HKW contributed to conception and design. GMQ, XS

contributed to the acquisition, analysis, and interpretation of data. XS and ZHL contributed to drafting the work. TGZ, ZHZ, and HKW contributed to revising it critically. All authors approved the final version to be published and agreed to be accountable for all aspects of the work.

\section{Funding}

This research was supported by the Natural Science Foundation of Shandong Province (ZR2016HL39), Yantai Science and Technology Project (2019YD020).

\section{Availability of data and materials}

In consideration of patient privacy, the datasets involved in this study are not publicly available, but the datasets generated and/or analyzed during the current study are available from the corresponding author on reasonable request.

\section{Declarations}

\section{Ethics approval and consent to participate}

The study was approved by the Ethics Committee of Yantai Yuhuangding Hospital on November 27, 2017 (registration number: YLYLLS [2018] 008).

Written informed consent was obtained from all participants.

\section{Consent for publication}

The consent for publication is not applicable because this study does not include any individual details, images, or videos.

\section{Competing interests}

The authors have no conflicts of interest to declare. 


\section{Author details}

'Department of Pathology, Affiliated Yantai Yuhuangding Hospital, Medical College of Qingdao University, Yantai, China. ${ }^{2}$ Department of Gynecology, Affiliated Yantai Yuhuangding Hospital, Medical College of Qingdao University, Yantai, China. ${ }^{3}$ Department of Pathology, People's Hospital of Rong cheng, Weihai, China. ${ }^{4}$ Department of Pathology, Yantai Muping District Traditional Chinese Medicine Hospital, Yantai, China. ${ }^{5}$ Department of Pathology, School of Medicine, Shandong University, Jinan, Shandong, China. ${ }^{6}$ Department of Pediatrics, Traditional Chinese Medicine Hospital of Rushan, Weihai, China. ${ }^{7}$ Department of Gynaecology and Obstetrics, Shanghai General Hospital, Shanghai Jiao Tong University School of Medicine, Shanghai, China.

\section{Received: 16 February 2020 Accepted: 18 May 2021} Published online: 29 June 2021

\section{References}

1. Wojcieszynski AP, Hullett CR, Medlin EE, Taunk NK, Shabason JE, Brower JV, et al. The role of radiation therapy in the treatment of stage II endometrial cancer: a large database study. Brachytherapy. 2018;17(4):645-52. https:/doi. org/10.1016/j.brachy.2018.02.001.

2. Makker V, Green AK, Wenham RM, Mutch D, Davidson B, Miller DS. New therapies for advanced, recurrent, and metastatic endometrial cancers. Gynecol Oncol Res Pract. 2017:4(1):19. https://doi.org/10.1186/s40661-017-0056-7.

3. Yeramian A, Moreno-Bueno G, Dolcet X, Catasus L, Abal M, Colas E, et al. Endometrial carcinoma: molecular alterations involved in tumor development and progression. Oncogene. 2013;32(4):403-13. https://doi. org/10.1038/onc.2012.76

4. Singh N, Hirschowitz L, Zaino R, Alvarado-Cabrero I, Duggan MA, Ali-Fehmi $R$, et al. Pathologic prognostic factors in endometrial carcinoma (other than tumor type and grade). Int J Gynecol Pathol. 2019;38(Suppl 1):S93-s113. https://doi.org/10.1097/PGP.0000000000000524.

5. Sanderson PA, Critchley HO, Williams AR, Arends MJ, Saunders PT. New concepts for an old problem: the diagnosis of endometrial hyperplasia. Hum Reprod Update. 2017;23(2):232-54. https://doi.org/10.1093/humupd/ dmw042.

6. Liu Y, Patel L, Mills GB, Lu KH, Sood AK, Ding L, et al. Clinical significance of CTNNB1 mutation and Wnt pathway activation in endometrioid endometrial carcinoma. J Natl Cancer Inst. 2014;106(9):dju245.

7. Handschumacher RE, Harding MW, Rice J, Drugge RJ, Speicher DW. Cyclophilin: a specific cytosolic binding protein for cyclosporin A. Science. 1984;226(4674):544-7.

8. Daum S, Schumann M, Mathea S, Aumuller T, Balsley MA, Constant SL, et al. Isoform-specific inhibition of cyclophilins. Biochemistry. 2009;48(26):6268-77. https://doi.org/10.1021/bi9007287.

9. Li Z, Zhao X, Bai S, Wang Z, Chen L, Wei Y, et al. Proteomics identification of cyclophilin a as a potential prognostic factor and therapeutic target in endometrial carcinoma. Mol Cell Proteomics. 2008;7(10):1810-23. https://doi. org/10.1074/mcp.M700544-MCP200

10. Choi KJ, Piao YJ, Lim MJ, Kim JH, Ha J, Choe W, et al. Overexpressed cyclophilin a in cancer cells renders resistance to hypoxia- and cisplatininduced cell death. Cancer Res. 2007;67(8):3654-62. https://doi.org/10.1158/ 0008-5472.CAN-06-1759.

11. Li Z, Min W, Gou J. Knockdown of cyclophilin a reverses paclitaxel resistance in human endometrial cancer cells via suppression of MAPK kinase pathways. Cancer Chemother Pharmacol. 2013;72(5):1001-11. https://doi. org/10.1007/s00280-013-2285-8

12. Carpentier M, Descamps L, Allain F, Denys A, Durieux S, Fenart $L$, et al. Receptor-mediated transcytosis of cyclophilin B through the blood-brain barrier. J Neurochem. 1999;73(1):260-70. https://doi.org/10.1046/j.1471-41 59.1999.0730260.x

13. Fang F, Flegler AJ, Du P, Lin S, Clevenger CV. Expression of cyclophilin B is associated with malignant progression and regulation of genes implicated in the pathogenesis of breast cancer. Am J Pathol. 2009;174(1):297-308. https://doi.org/10.2353/ajpath.2009.080753.

14. Rycyzyn MA, Clevenger CV. The intranuclear prolactin/cyclophilin B complex as a transcriptional inducer. Proc Natl Acad Sci U S A. 2002;99(10):6790-5. https://doi.org/10.1073/pnas.092160699.

15. Kaul A, Stauffer S, Berger C, Pertel T, Schmitt J, Kallis S, et al. Essential role of cyclophilin a for hepatitis $C$ virus replication and virus production and possible link to polyprotein cleavage kinetics. PLoS Pathog. 2009;5(8): e1000546. https://doi.org/10.1371/journal.ppat.1000546.

16. Zhao K, Li J, He W, Song D, Zhang X, Zhang D, et al. Cyclophilin B facilitates the replication of Orf virus. Virol J. 2017;14(1):114. https://doi.org/10.1186/ s12985-017-0781-x.

17. Bukrinsky MI. Cyclophilins: unexpected messengers in intercellular communications. Trends Immunol. 2002;23(7):323-5. https://doi.org/10.101 6/S1471-4906(02)02237-8.

18. Rycyzyn MA, Reilly SC, O'Malley K, Clevenger CV. Role of cyclophilin B in prolactin signal transduction and nuclear retrotranslocation. Mol Endocrinol. 2000;14(8):1175-86.

19. Fang F, Zheng J, Galbaugh TL, Fiorillo AA, Hjort EE, Zeng X, et al. Cyclophilin $B$ as a co-regulator of prolactin-induced gene expression and function in breast cancer cells. J Mol Endocrinol. 2010;44(6):319-29. https://doi.org/10.1 677/JME-09-0140.

20. Bauer K, Kretzschmar AK, Cvijic H, Blumert C, Loffler D, Brocke-Heidrich K, et al. Cyclophilins contribute to Stat3 signaling and survival of multiple myeloma cells. Oncogene. 2009;28(31):2784-95. https://doi.org/10.1038/ onc.2009.142.

21. Kim Y, Jang M, Lim S, Won H, Yoon KS, Park JH, et al. Role of cyclophilin B in tumorigenesis and cisplatin resistance in hepatocellular carcinoma in humans. Hepatology. 2011;54(5):1661-78. https://doi.org/10.1002/hep.24539.

22. Guo F, Zhang Y, Zhao CN, Li L, Guo YJ. Effects of gene silencing of CypB on gastric cancer cells. Asian Pac J Trop Med. 2015;8(4):319-24. https://doi. org/10.1016/S1995-7645(14)60338-2.

23. Hartmann E, Wollenberg B, Rothenfusser S, Wagner M, Wellisch D, Mack B, et al. Identification and functional analysis of tumor-infiltrating plasmacytoid dendritic cells in head and neck cancer. Cancer Res. 2003;63(19):6478-87.

24. Choi JW, Schroeder MA, Sarkaria JN, Bram RJ. Cyclophilin B supports Myc and mutant p53-dependent survival of glioblastoma multiforme cells. Cancer Res. 2014;74(2):484-96. https://doi.org/10.1158/0008-5472.CAN-130771.

25. Ray P, Rialon-Guevara KL, Veras E, Sullenger BA, White RR. Comparing human pancreatic cell secretomes by in vitro aptamer selection identifies cyclophilin B as a candidate pancreatic cancer biomarker. J Clin Invest. 2012; 122(5):1734-41. https://doi.org/10.1172/JCl62385.

26. Lazaro E, Amayra I, Lopez-Paz JF, Martinez O, Perez M, Berrocoso S, et al. Instrument for assessing the ability to identify emotional facial expressions in healthy children and in children with ADHD: the FEEL test. J Atten Disord. 2019:23(6):563-9. https://doi.org/10.1177/1087054716682335.

27. Yang H, Chen J, Yang J, Qiao S, Zhao S, Yu L. Cyclophilin a is upregulated in small cell lung cancer and activates ERK1/2 signal. Biochem Biophys Res Commun. 2007;361(3):763-7. https://doi.org/10.1016/j.bbrc.2007.07.085.

28. Campa MJ, Wang MZ, Howard B, Fitzgerald MC, Patz EF Jr. Protein expression profiling identifies macrophage migration inhibitory factor and cyclophilin a as potential molecular targets in non-small cell lung cancer. Cancer Res. 2003:63(7):1652-6.

29. Shen J, Person MD, Zhu J, Abbruzzese JL, Li D. Protein expression profiles in pancreatic adenocarcinoma compared with normal pancreatic tissue and tissue affected by pancreatitis as detected by two-dimensional gel electrophoresis and mass spectrometry. Cancer Res. 2004;64(24):9018-26. https://doi.org/10.1158/0008-5472.CAN-04-3262.

30. Mikuriya K, Kuramitsu Y, Ryozawa S, Fujimoto M, Mori S, Oka M, et al. Expression of glycolytic enzymes is increased in pancreatic cancerous tissues as evidenced by proteomic profiling by two-dimensional electrophoresis and liquid chromatography-mass spectrometry/mass spectrometry. Int J Oncol. 2007;30(4):849-55.

31. Lim SO, Park SJ, Kim W, Park SG, Kim HJ, Kim Yl, et al. Proteome analysis of hepatocellular carcinoma. Biochem Biophys Res Commun. 2002;291(4): 1031-7. https://doi.org/10.1006/bbrc.2002.6547.

32. Chen J, He QY, Yuen AP, Chiu JF. Proteomics of buccal squamous cell carcinoma: the involvement of multiple pathways in tumorigenesis. Proteomics. 2004;4(8):2465-75. https://doi.org/10.1002/pmic.200300762.

33. Yurchenko V, O'Connor M, Dai WW, Guo H, Toole B, Sherry B, et al. CD147 is a signaling receptor for cyclophilin B. Biochem Biophys Res Commun. 2001; 288(4):786-8. https://doi.org/10.1006/bbrc.2001.5847.

34. Melchior A, Denys A, Deligny A, Mazurier J, Allain F. Cyclophilin B induces integrin-mediated cell adhesion by a mechanism involving CD98dependent activation of protein kinase C-delta and p44/42 mitogenactivated protein kinases. Exp Cell Res. 2008;314(3):616-28. https://doi.org/1 0.1016/j.yexcr.2007.11.007. 
35. Pakula R, Melchior A, Denys A, Vanpouille C, Mazurier J, Allain F. Syndecan1/CD147 association is essential for cyclophilin B-induced activation of p44/ 42 mitogen-activated protein kinases and promotion of cell adhesion and chemotaxis. Glycobiology. 2007;17(5):492-503. https://doi.org/10.1093/ glycob/cwm009.

36. Yang JM, O'Neill $P$, Jin W, Foty R, Medina DJ, Xu Z, et al. Extracellular matrix metalloproteinase inducer (CD147) confers resistance of breast cancer cells to Anoikis through inhibition of Bim. J Biol Chem. 2006;281(14):9719-27. https://doi.org/10.1074/jbc.M508421200.

37. Teng MR, Huang JA, Zhu ZT, Li H, Shen JF, Chen Q. Cyclophilin B promotes cell proliferation, migration, invasion and angiogenesis via regulating the STAT3 pathway in non-small cell lung cancer. Pathol Res Pract. 2019;215(6): 152417. https://doi.org/10.1016/j.prp.2019.04.009.

38. Holland CM, Day K, Evans A, Smith SK. Expression of the VEGF and angiopoietin genes in endometrial atypical hyperplasia and endometrial cancer. Br J Cancer. 2003;89(5):891-8. https://doi.org/10.1038/sj.bjc.6601194.

\section{Publisher's Note}

Springer Nature remains neutral with regard to jurisdictional claims in published maps and institutional affiliations.

Ready to submit your research? Choose BMC and benefit from:

- fast, convenient online submission

- thorough peer review by experienced researchers in your field

- rapid publication on acceptance

- support for research data, including large and complex data types

- gold Open Access which fosters wider collaboration and increased citations

- maximum visibility for your research: over $100 \mathrm{M}$ website views per year

At BMC, research is always in progress.

Learn more biomedcentral.com/submissions 